\title{
The Effect of the Corrugation Height on Temperature Distribution in Primary Surface Recuperator for $30 \mathrm{~kW}$ Microturbine
}

\author{
Rilrada Sangsawang, Thanate Matum, and Udomkiat Nontakaew
}

\begin{abstract}
This research paper presents the effect of the corrugation height of the corrugated foils on temperature distributions in the counter-flow primary surface recuperator (PSR). The flow channel of study is in the form of rectangular channel with semicircular ends. The primary surface recuperator is designed based on the microturbine recuperator requirements and the $30 \mathrm{~kW}$ microturbine operating parameters. The exact solutions for temperature distribution, obtained from the thermodynamic modeling with the help of the analytical method and Laplace Transform, for both fluids are solved and are verified by computational fluid dynamic program package. The results show that the corrugation height of the foils has direct effect to the convective heat transfer coefficient, the Nusselt number, and also the recuperator effectiveness.
\end{abstract}

Index Terms-Effectiveness, heat exchanger, microturbine recuperator.

\section{INTRODUCTION}

A recuperator is a direct transfer type of heat exchanger that is extensively used in microturbine systems. The thermal efficiency of the microturbine is about $20 \%$ or less if no recuperator is applied and increases to about $30 \%$ for the system with recuperator operating at $87 \%$ effectiveness. Since the recuperator costs about $25-30 \%$ of the total power plant cost, therefore the recuperator must have high performance with minimum cost. The contemporary recuperator design for the microturbine system use prime surfaces geometry on hot and cold fluid sides with no brazing stacking, and welded at the side edges to form airflow passage. This configuration prevents the leaks and mixing of the fluids. Since the main attributes of primary surface recuperators are the surface geometry is $100 \%$ effective and sealing can be achieved by welding, this type of recuperator is therefore meet all recuperator design requirement for microturbine application as stated in [1].

Although, there are many researches and studies about recuperator, most of them are mainly focus on fabrication and construction. The theoretical researches about recuperator are very little. R.K.Shah [1] summarized the developments of compact heat exchangers for microturbine. The research paper reviewed the recuperator requirements for

Manuscript received January 12, 2015; revised June 12, 2015. This work was supported in part by the Energy Policy and Planning Office, Ministry of Energy, Royal Thai Government, and King Mongkut's University of Technology North Bangkok.

The authors are with the Department of Mechanical and Aerospace Engineering, Faculty of Engineering, King Mongkut's University of Technology North Bangkok, Bangkok, Thailand (e-mail: rilradas@yahoo.com, m.thanate@yahoo.com, unk@kmutnb.ac.th). microturbine application. Colin F. McDonald [2] described the recuperator considerations for future higher efficiency microturbines. The gas turbine recuperator technology is also discussed in this research paper. Muley and Sunden [3] described a primary surface recuperator with counter flow arrangement developed by Honeywell Corporation. The plates have corrugation in heat transfer region and are stacked and welded at periphery to form alternate gas and airflow passage. Liu Zhenyu [4] presented the design and analysis of primary surface recuperator for microturbine using multi-objective optimization method. Su-Jong Yoon [5] developed the general methods for thermal design and cost estimation of printed circuit heat exchanger. The numerical study on cross-flow printed circuit heat exchanger for advanced small modular reactors are also presented.

The purpose of this research paper is to study of the effect of the corrugation height on temperature distribution and heat transfer in the primary surface recuperator (PSR) using analytical method, thermal design process, and computational fluid dynamics. The heat transfer surface of study is in the form of rectangular channel with semicircular ends and the exhausted gas and the compressed air are in the counter flow directions. The primary surface recuperator is designed based on the recuperator design requirement and 30 $\mathrm{kW}$ microturbine operating parameter.

\section{PRIMARY SURface RECUPERATOR GEOMETRY,} THERMODYNAMIC MODELING AND ANALYTICAL METHODS

The domain of the study is the matrix contains the heat transfer surface. The honeycomb core of primary surface recuperator is made up of 304 stainless steel corrugated foils. These corrugated foils are heat transfer surface of the recuperator that is in direct contact with both the exhausted gas (from the turbine exit) and the compressed air (from the compressor) in the counter-flow direction.

The transfer of enthalpy, from the exhausted gas to the compressed air, occurs by conduction through the 304 stainless steel corrugated foils. A schematic of the counter-flow primary surface recuperator is shown in Fig.1.

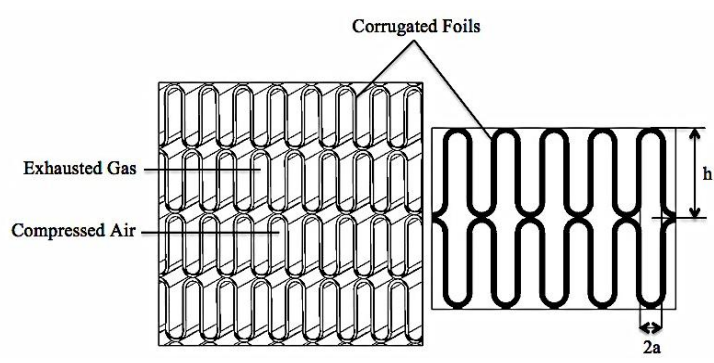

Fig. 1. The cross section of the primary surface recuperator core. 
TABLE I: NOMENCLATURE

Nomenclature, Greeks, Symbols and Subscript

$a \quad$ radius of the semicircular ends $[m]$

$A_{O} \quad$ flow channel surface area $\left[\mathrm{m}^{2}\right]$

$A_{t} \quad$ overall heat transfer surface area $\left[\mathrm{m}^{2}\right]$

$c_{p} \quad$ specific heat capacity $[\mathrm{kJ} / \mathrm{kg} \times \mathrm{K}]$

$D_{h} \quad$ hydraulic diameter $[m]$

$t \quad$ resistance coefficient

$h \quad$ height of the corrugated foils [ $\mathrm{m}$ ]

$h_{j} \quad$ convection heat transfer coefficient $\left[\mathrm{W} / \mathrm{m}^{2} \times K\right]$

$k \quad$ thermal conductivity [ $W / m \times K$ ]

$L \quad$ length of the recuperator $[m]$

$\dot{m} \quad$ mass flow rate $[\mathrm{kg} / \mathrm{s}]$

$N \quad$ number of flow channel

NTU number of transfer unit $\left(=U_{o} A_{t} / \dot{m} c_{p}\right)$

$N u \quad$ Nusselt number $(=h D / k)$

$P \quad$ Pressure $[\mathrm{Pa}]$

Pr Prandtl number

Re Reynolds number

$T \quad$ temperature $[K]$

$t \quad$ plate thickness [ $m$ ]

$U_{o} \quad$ overall heat transfer coefficient $\left[\mathrm{W} / \mathrm{m}^{2} \times K\right]$

$V \quad$ fluid velocity $[\mathrm{m} / \mathrm{s}]$

$\varepsilon \quad$ recuperator effectiveness

$\theta$ dimensionless temperature

$\xi \quad$ normalized length in x-coordinate

$1, h \quad$ exhausted gas (primary fluid)

2, $c \quad$ compressed air (secondary fluid)

$\mathrm{x}$-direction

y-direction

For a single-pass counter flow and both unmixed fluids, the energy balance for the flow channel that can be written using the first law of thermodynamics can be shown, with the assumption of uniform distribution of the total heat transfer surface area along the flow channel, as follows:

$$
\begin{aligned}
& \left(\dot{m} c_{p}\right)_{1} d T_{1} / d x=(U A / L)\left(T_{2}-T_{1}\right) \\
& \left(\dot{m} c_{p}\right)_{2} d T_{2} / d x=(U A / L)\left(T_{2}-T_{1}\right)
\end{aligned}
$$

The above equations can be solved with the help of dimensionless parameter as

$$
\theta_{j}=\left(T_{j}-T_{1, i n}\right) /\left(T_{2, i n}-T_{1, i n}\right) \quad, \xi=x / L \text { for } j=1,2
$$

Therefore the Eq. 1 - Eq.3 become

$$
\begin{gathered}
\left(d \theta_{1} / d \xi\right)+N T U_{1}\left(\theta_{1}-\theta_{2}\right)=0 \\
\left(d \theta_{2} / d \xi\right)-N T U_{1} R_{1}\left(\theta_{1}-\theta_{2}\right)=0 \\
N T U_{1}=U A /\left(\dot{m} C_{p}\right)_{1}, N T U_{2}=U A /\left(\dot{m} C_{p}\right)_{2},
\end{gathered}
$$

$$
R_{1}=N T U_{2} / N T U_{1}
$$

Applied the boundary conditions at the inlets $(\xi=0$ and $\xi$ $=L$ ), the general form of solutions can be obtained using the Laplace transforms method as shown.

$$
\begin{gathered}
\theta_{1}(\xi)=\left(1-\exp \left(-\xi N T U_{1}\left(1-R_{1}\right)\right)\right) /\left(1-R_{1} \exp \left(-N T U_{1}\left(1-R_{1}\right)\right)\right) \\
\theta_{2}(\xi)=\left(1-R_{1} \exp \left(-\xi N T U_{1}\left(1-R_{1}\right)\right)\right) /\left(1-R_{1} \exp \left(-N T U_{1}\left(1-R_{1}\right)\right)\right)
\end{gathered}
$$

The exact solutions for temperature distribution of both fluids are obtained as

$$
\begin{gathered}
T_{1}(x)=T_{1, i n}+\left(T_{2, i n}-T_{1, i n}\right) \cdot \\
\left(\left(1-\exp \left(-N T U_{1} X\left(1-R_{1}\right)\right) / L\right) /\left(1-R_{1} \exp \left(-N T U_{1}\left(1-R_{1}\right)\right)\right)\right) \\
T_{2}(x)=T_{1, i n}+\left(T_{2, i n}-T_{1, i n}\right) \cdot \\
\left(\left(1-R_{1} \exp \left(-N T U_{1} x\left(1-R_{1}\right)\right) / L\right) /\left(1-R_{1} \exp \left(-N T U_{1}\left(1-R_{1}\right)\right)\right)\right)
\end{gathered}
$$

\section{Thermal Design, Thermal Design Process, And ANALYTICAL SOLUTION}

In order to determine the size of the recuperator, the dimensions of the recuperator $\left(L_{X}, L_{Y}\right.$, and $\left.L_{Z}\right)$ are assumed. The flow channels are considered as the rectangular channel with semicircular ends. The channel has the dimension as shown in the Fig.1. The exhausted gas flow channel is between two consecutive compressed air flow channels. From the assumed geometry information, the number of compressed air flow channel in the $\mathrm{x}$-direction and $\mathrm{y}$-direction are determined as

$$
\begin{aligned}
& N_{c, x}=L_{x} /(2 a+t) \\
& N_{c, y}=L_{y} /(2 h+2 t)
\end{aligned}
$$

The number of exhausted gas flow channel in $\mathrm{x}$-direction and y-direction are

$$
\begin{aligned}
& N_{h, x}=N_{c, x}-1 \\
& N_{h, y}=N_{c, y}-1
\end{aligned}
$$

The heat transfer surface area $\left(A_{\mathrm{o}}\right)$, the frontal area $(A)$, the perimeter $(P)$, and the hydraulic diameter $\left(D_{h}\right)$ of the flow channel are also developed as

$$
\begin{gathered}
A_{o}=2 L_{z}(2 h+a(\pi-2)) \\
A=4 a(h-a)+\pi a^{2} \\
P=4 h+2 a(\pi-2) \\
D_{h}=2\left(4 a h+a^{2}(\pi-4)\right) /(2 h+a)
\end{gathered}
$$

The mass flow rate of the fluids is given based on the 30 $\mathrm{kW}$-microturbine operating conditions. The velocity of the exhausted gas (primary fluid) and the compressed air (secondary fluid) are calculated as follows

$$
V_{j}=\dot{m} / \rho_{j} A N_{j, x} N_{j, y}, \text { for } j=1,2
$$


The Reynolds number and Prandtl number of both fluids are also calculated as

$$
\begin{gathered}
\operatorname{Re}_{j}=\rho_{j} V_{j} D_{h} / \mu_{j}, \text { for } j=1,2 \\
\operatorname{Pr}_{j}=c_{p, j} \mu_{j} / k_{j}
\end{gathered}
$$

The heat transfer coefficient is calculated by empirical heat transfer correlation. The heat transfer correlation applied in this paper is based on $[4,7]$ and is shown as follows

$$
\begin{gathered}
N u=0.0031 \operatorname{Re}^{1.18} \operatorname{Pr}^{0.4}(h / a)^{0.19}, \\
\operatorname{Re}<1000 \text { and } 1 \leq h / a \leq 9
\end{gathered}
$$

The heat transfer coefficient for the exhausted gas and the compressed air are calculated as

$$
h_{j}=N u_{j} k_{j} / D_{h} \text {, for } j=1,2
$$

The overall heat transfer coefficient of counter-flow primary surface recuperator is determined as

$$
U_{o}=1 /\left(\left(1 / h_{1}\right)+(t / k)+\left(1 / h_{2}\right)\right)
$$

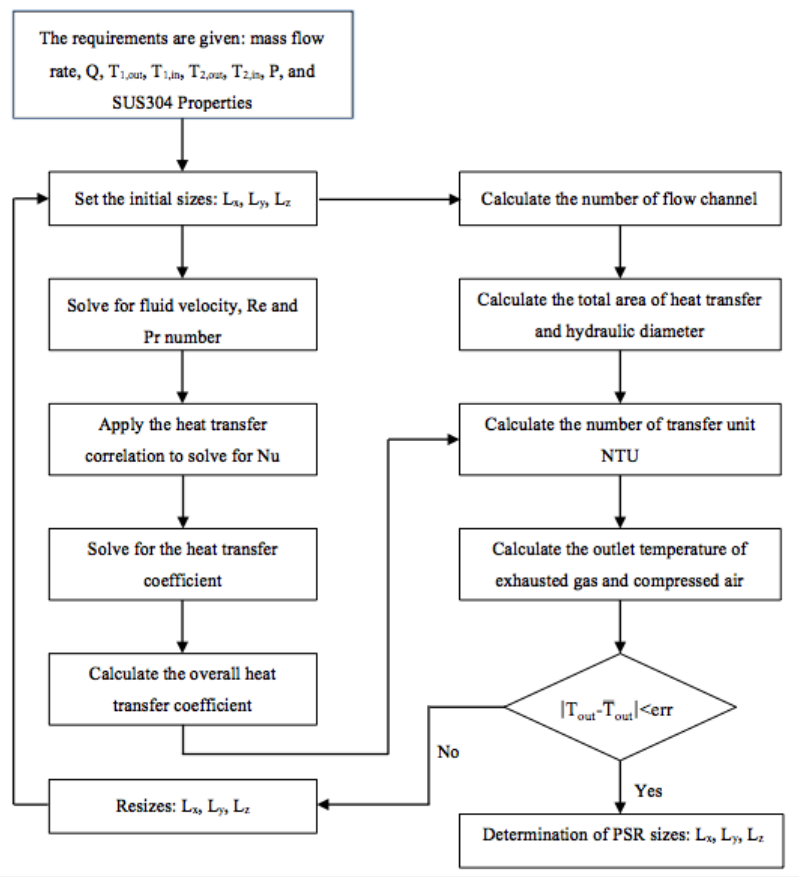

Fig. 2. PSR thermal design process.

\section{RESUlTS AND CONCLUSIONS}

To meet heat requirements of the $30 \mathrm{~kW}$ microturbine conditions, the size of PSR is calculated through thermal design process [4] and built-in function of the MATLAB program, as shown in Fig. 2. The analytical solutions for temperature distributions along the PSR length, as shown in Eq.8 and Eq.9, are verified against the solution from computational fluid dynamic program package which is shown in Fig. 3. The influences of the h/a ratio on PSR effectiveness and the outlet temperature of PSR are presented in Fig. 4. The effects of the height of the corrugated foils on convection heat transfer coefficient, Nusselt number, and PSR effectiveness are shown in Fig. 5. and Fig. 6. According to the figures, the increase in the height of the corrugated foil when the radius of the semicircular ends are treated as constant leads to the higher in the convection heat transfer coefficient, Nusselt number and PSR effectiveness. Furthermore, based on the numerical investigation, the increase in the radius of the semicircular ends when the height of the corrugated foil is treated as constant leads to the lower in the convection heat transfer coefficient, Nusselt number and PSR effectiveness. It can be concluded that the corrugation height of the foils has direct effect to the heat transfer and temperature distribution in primary surface recuperator designed for $30 \mathrm{~kW}$ microturbine. This investigated data are valuable to the design of primary surface recuperator for microturbine application.

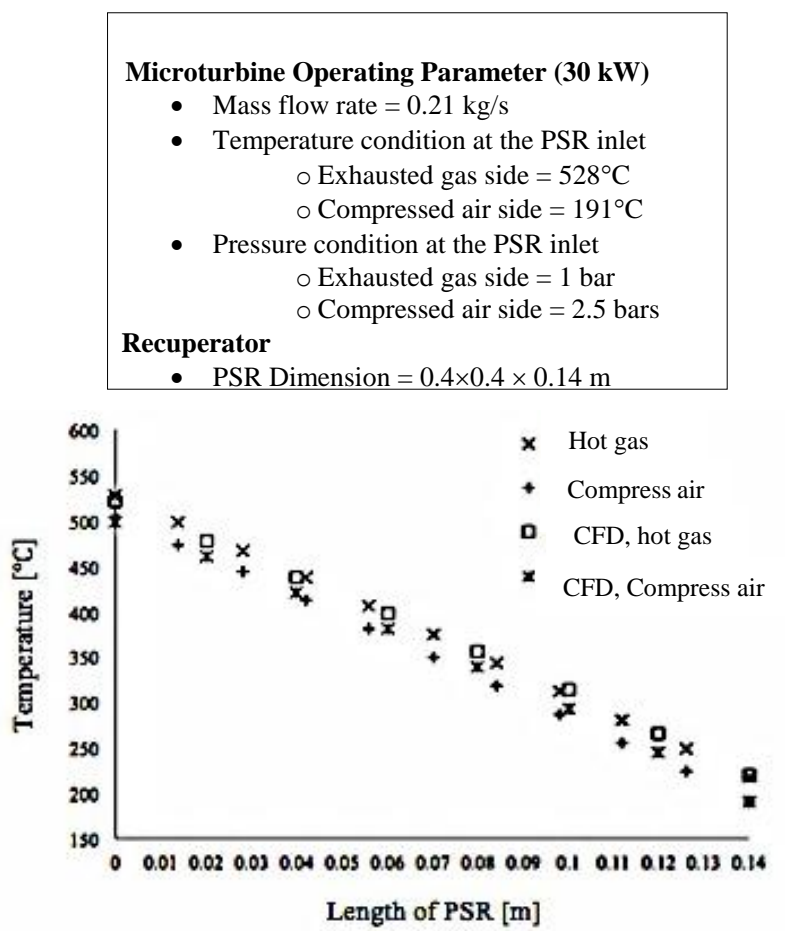

Fig. 3 The analytical solutions for temperature distributions along the PSR length (Eq.8-Eq.9) are verified against the solution from computational fluid dynamic program package.

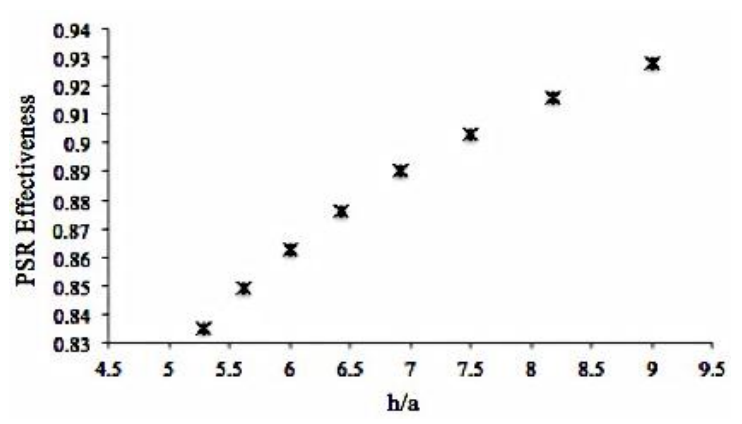

Fig. 4 The influences of the ratio h/a on PSR effectiveness.

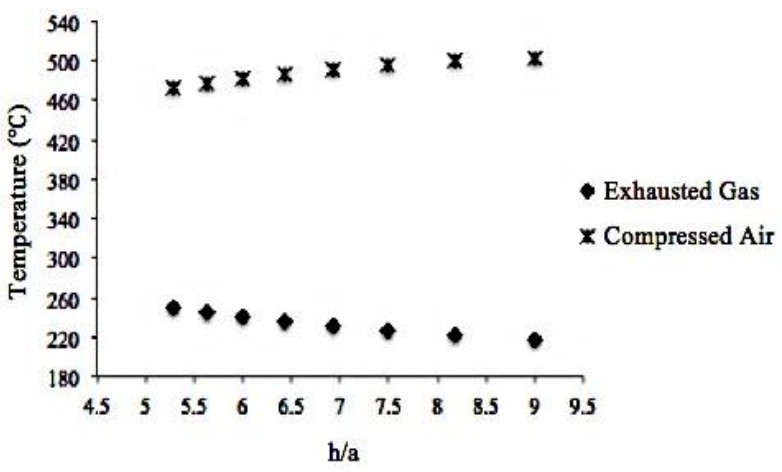

Fig. 5 The influences of the ratio h/a temperature at the PSR exit. 


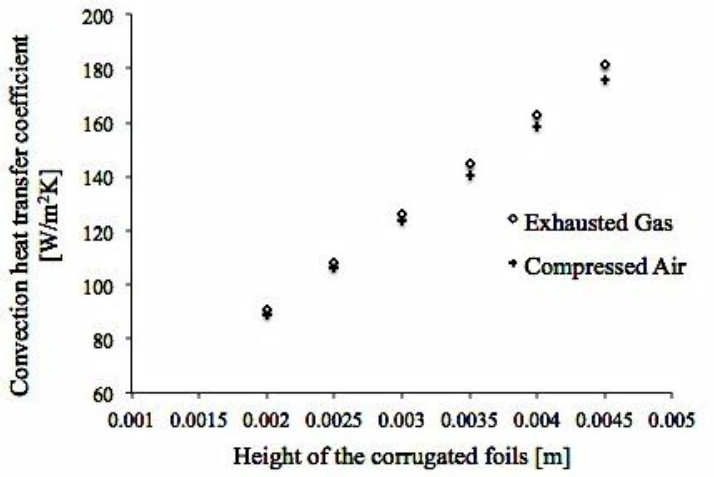

Fig. 6. The influences of the height of the corrugated foils on convection heat transfer coefficient

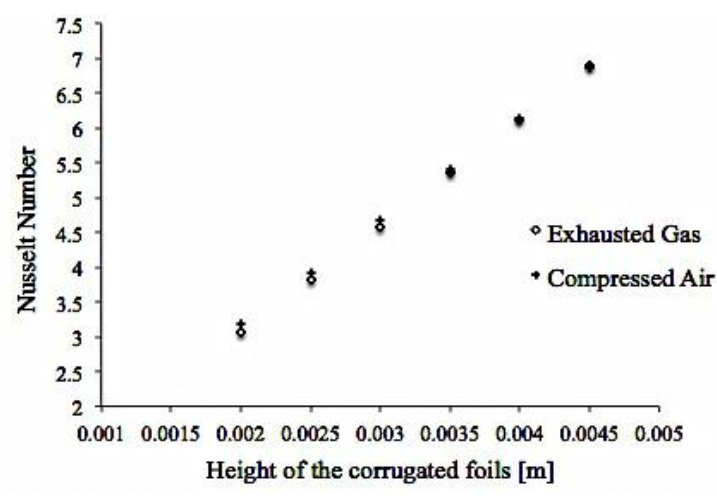

Fig. 7 The influences of the height of the corrugated foils on Nusselt number on exhausted gas side and compressed air side

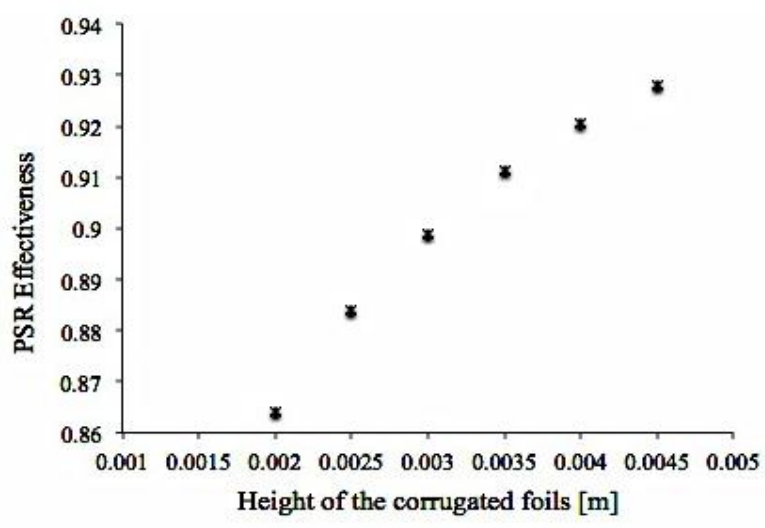

Fig. 8 The influences of the height of corrugated foils on the PSR effectiveness.

\section{REFERENCES}

[1] R. K .Shah, "Compact heat exchanger for microturbines," Micro Gas Turbine, Educational Note, pp. 1-2.
[2] C. F. McDonald, "Recuperator considerations for future higher efficiency microturbines," Applied Thermal Engineering, vol. 23, no. 12, 2003, pp. 1463-1487.

[3] C. Y. Lin, M. Wu, J. A. Bloom, I. J. Cox, and M. Miller, "Rotation, scale, and translation resilient public watermarking for images," IEEE Trans. Image Process., vol. 10, no. 5, pp. 767-782, May 2001.

[4] A. Muley and B. Sunden, "Advanced in recuperator technology for gas turbine systems," Linear Networks and Systems, 1993, pp. 123-135.

[5] Z. N. Liu and C. Huier, "Multi-objective optimization design analysis of primary surface recuperator for microturbines," Applied Thermal Engineering, vol. 28, 2008, pp. 601-610.

[6] S. J. Yoon, P. Sabharwall, and E. S. Kim, "Numerical study on crossflow printed circuit heat exchanger for advanced small modular reactors," International Journal of Heat and Mass Transfer, vol. 70 2014, pp. 250-263.

[7] L. Z. Zhang, "Laminar flow and heat transfer in plate-fin triangular ducts in thermally developing entry region," International Journal of Heat and Mass Transfer, vol. 50, 2007, pp. 1637-1640.

[8] M. D. Xin, P. J. Zhang, and J. Yang, "Convective heat transfer of air in micro-rectangular channels," Journal of Engineering Thermophysics, vol. 16 , no. 1, 1995, pp. 86-90.

Rilrada Sangsawang was born in 1981, in Bangkok, Thailand. She received her bachelor's degree in mechanical engineering in 2000 and her master's degree in applied mathematics in 2008 from King Mongkut's University of Technology North Bangkok. She is now a Ph.D. candidate in mechanical and aerospace engineering from King Mongkut's University of Technology North Bangkok.

She was a special lecturer at King Mongkut's University of Technology North Bangkok in 2010. In 2012 she worked as the project manager at Development of Machinery and Industrial Equipment (DMIE Research Center). She is now a chief researcher of the TNE Limited Partnership.

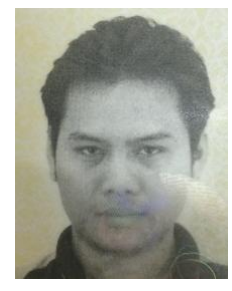

Thanate Matum was born in 1984, in Prachinburi, Thailand. He received his bachelor's degree and his master's degree in mechanical engineering in 2008 from King Mongkut's University of Technology North Bangkok. He is now a Ph.D. candidate in mechanical and aerospace engineering from King Mongkut's University of Technology North Bangkok

He was a section head of Research and Development, Engineering Department, T.N. Metal Works, Thailand. He worked as the engineering manager at Development of Machinery and Industrial Equipment (DMIE Research Center). He is now a chief researcher of the TNE Limited Partnership.

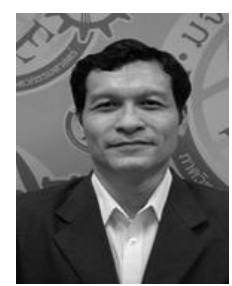

Udomkiat Nontakaew was born in 1962, in Suratthani, Thailand. He received his bachelor's degree and his master's degree in mechanical engineering from King Mongkut's University of Technology North Bangkok. He received his doctoral's degree in DEA (Fluid Mechanics), Docteur de I'Universite de Poitiers (Fluid Mechanics) Universite de Poitiers, France.

He is now the dean of the Faculty of Engineering, King Mongkut's University of Technology North Bangkok, Bangkok, Thailand. 